\title{
Sistem Pendukung Keputusan Karyawan Teladan Menggunakan Algoritma SAW Pada PT Semesta Citra Media
}

\author{
Muhammad Rizki Fajar ${ }^{1}$, Eugenius Kau Suni ${ }^{2}$ \\ 1,2 Fakultas Teknik Informatika, Universitas MercuBuana \\ JI. Menteng Raya No 29, Menteng, Jakarta Selatan, Indonesia
}

e-mail: ${ }^{1} 41517110176 @ s t u d e n t . m e r c u b u a n a . a c . i d,{ }^{2}$ eugenius@mercubuana.ac.id

\begin{abstract}
Informasi Artikel Diterima: 26-05-2021 Direvisi: 25-06-2021 Disetujui: 29-06-2021
Abstrak

Karyawan berperan penting untuk mewujudkan visi dan misi perusahaan sehingga dianggap asset penting dan berpengaruh besar untuk kemajuan perusahaan, tanpa adanya karyawan perusahaan tidak bisa berjalan. Karyawan yang merupakan elemen vital untuk tumbuh kembangnya suatu perusahaan perlu selalu dijaga dan ditingkatkan kualifikasinya. Penilaian kinerja karyawan menjadi strategis untuk mengetahui kualitas kinerja yang dimiliki oleh karyawan tersebut. Namun karena banyaknya karyawan yang akan di pilih di PT SCMedia menjadi kendala dalam pemilihan karyawan teladan dan pada penilaian karyawan ini masih menggunakan secara manual dan belum adanya metode yang tepat untuk melakukan pencarian karyawan teladan. Untuk mengatasi permasalahan tersebut perlu dibuat sistem pendukung keputusan mencari karyawan teladan menggunakan metode SAW agar pemilihan penilaian karyawan teladan tepat dan akurat dikarenakan metode saw dapat menghasilkan nilai terbesar hingga terendah yang nantinya akan dijadikan alternatif. Penelitian ini bertujuan merancang sebuah sistem pendukung keputusan untuk memilih karyawan teladan di PT SCMedia. Di sini diperlukan sebuah sistem informasi berbasis komputer termasuk sistem berbasis pengetahuan yang digunakan untuk mendukung pendukung keputusan. Penelitian ini menggunakan metode Simple Additive Weighting (SAW) untuk menghitung penjumlahan terbobot yang didapat dari rating kinerja pada setiap alternatif di semua atribut kinerja. Hasil dari penelitian menggunakan metode saw ini menunjukkan peringkat dari peringkat 1 sampai 40 yang dimana pada peringkat 1 sampai 3 akan ditetapkan sebagai karyawan teladan yang mendapatkan penambahan gaji dan reward berupa liburan dan cuti.
\end{abstract}

Kata Kunci: Sistem Pendukung Keputusan, Simple Additive Weighting

\begin{abstract}
Employees are important to realize the vision and mission so that they are considered important and have a big influence on the progress of the company, without employees it cannot run. Employees who are vital elements for the growth and development of a company need to always be maintained and their qualifications improved. employee performance appraisal becomes a strategy to determine the quality of the performance possessed by the employee. However, because of the large number of employees who will be selected at PT SCMedia, it becomes an obstacle in the selection of exemplary employees and in the assessment of these employees, they are still using it manually and there is no proper method to find exemplary employees. To overcome this problem, it is necessary to make a decision-making system to look for examples using the SAW method so that the assessment of exemplary employees is appropriate and because the viewing method can produce the lowest value which will be used as an alternative. This study aims to design a decision-making system to select exemplary employees at PT SCMedia. Here we need a computer-based information system, including a knowledge-based system that is used to support decision making. This study uses the Simple Additive Weighting (SAW) method to calculate the weighted sum obtained from the performance ratings on each alternative in all performance attributes. The results of the research using this viewing method show rankings from 1 to 40 , in which ranks 1 to 3 will be designated as exemplary employees who get additional salaries and awards in the form of holidays and leave.
\end{abstract}

Keywords: Decision Making System, Simple Additive Weighting, SCMedia 


\section{Pendahuluan}

Karyawan merupakan Sumber Daya Manusia (SDM) yang berperan sangat penting untuk mewujudkan suatu visi dan misi dalam sebuah perusahaan. Karyawan juga sangat berpengaruh besar untuk kemajuan perusahaan serta kelangsungan hidup sebuah perusahaan dalam persaingan bisnis (Alamsyah, 2020). Sumber Daya Manusia merupakan modal dasar dalam pembangunan perusahaan, karena SDM merupakan modal dasar maka perusahaan harus mengembangkan kualitas SDM dimana salah satunya berupa seleksi karyawan teladan.

PT Semesta Citra Media (SCMedia) adalah perusahaan swasta nasional yang bergerak di bidang bisnis jaringan telekomunikasi, yang dimana PT SCMedia melakukan memiliki banyak karyawan untuk memajukan perkembangan PT SCMedia (Somya \& Wahyudi, 2020). PT SCMedia tidak akan berjalan tanpa adanya seorang karyawan karena karyawan merupakan elemen vital tumbuh kembangnya suatu perusahaan yang perlu selalu dijaga dan ditingkatkan kualifikasinya (Saefulloh et al., 2017). Penilaian kinerja karyawan merupakan persoalan yang penting dalam mengelola kinerja. $\mathrm{Hal}$ ini ditujukan untuk mengetahui seberapa besar kualitas kinerja yang dimiliki oleh karyawan tersebut. Dan penilaian karyawan ini lebih bertujuan untuk menentukan karyawan terbaik dan memberikan suatu reward berupa tambahan kenaikan gaji, dan pemberian penghargaan yang kinerjanya dianggap memuaskan oleh perusahaan, karena kontribusi positif dalam kemajuan perusahaan.Selain itu pemberian bonus juga dapat memotivasi karyawan yang lainnya agar dapat bekerja lebih giat lagi. Memunculkan karyawan teladan setiap tahun dapat menjadi strategi perusahaan untuk memacu kinerja karyawan (Taufiq \& Permana, 2018). Namun PT SCMedia masih sulit untuk menentukan karyawan telada bedasarkan standar dari perusahaan .

Permasalahan yang terjadi pada PT SCMedia belum adanya metode yang tepat untuk melakukan pencarian karyawan teladan. Sehingga menyebabkan manager kesulitan untuk menentukan karyawan karyawan yang berhak mendapatkan penambahan kenaikan gaji dan reward karena belum adanya aplikasi yang mendukung untuk menentukan karyawan teladan tersebut (Taufiq \& Permana, 2018). Untuk mengatasi permasalahan tersebut perlu dibuat sistem pendukung keputusan mencari karyawan teladan menggunakan metode SAW agar pemilihan penilaian karyawan teladan tersebut tepat dan akurat dikarenakan metode saw dapat menghasilkan nilai terbesar hingga terendah yang nantinya akan dijadikan alternatif. Batasan masalah pada penelitian ini adalah : 1. Pada penilitan ini peniliti menggunakan algoritma SAW, karena metode SAW ini mampu menyeleksi alternatif terbaik dari sejumlah pilihan, dalam hal ini alternatif pilihan yang dimaksud yaitu yang berhak menerima reward berdasarkan kriteria-kriteria yang ditentukan. Penelitian dilakukan dengan mencari nilai bobot untuk setiap atribut, kemudian dilakukan proses perankingan yang akan menentukan alternatif yang optimal, yaitu karyawan teladan. 2. Metode Simple Additive Weighting (SAW) memiliki nilai bobot dari masing-masing data kriteria dan data crips. 3. Implementasi awal aplikasi ini khusus untuk kebutuhan manager HUB Operation untuk memilih karyawan teladan yang akan diajukan kepada divisi HRD (Somya \& Wahyudi, 2020).

Pada penelitian sebelumnya yang berjudul Sistem Informasi Rekrutmen Karyawan Berbasis WEB Menggunakan Algoritma Simple Additive Weighting (SAW) Membahas sebuah sistem perekrutan karyawan masih menggunakan cara sistem manual, seperti menerima berkas calon karyawan, memberikan test sehingga membutuhkan waktu yang lama. Hasil yang terdapat pada penelitian tersebut berupa berbasis website dan Menghasilkan sebuah informasi yang cepat untuk melakukan rekrutmen karyawan secara online dari variabel yang telah ditentukan seperti : kelengkapan data, pengumpulan berkas, dan soal ujian psikotest. Dari variabel tersebut apabila terpenuhi maka sistem akan memperoses dari ujian para kandidat, sehingga menampilkan data-data kandidat yang pantas yang akan direkrut (Alamsyah, 2020).

Pada penelitian sebelumnya yang berjudul Penerapan Metode Simple Additive Weighting (SAW) Pada Sakinah Supermarket Untuk Pemilihan Karyawan Terbaik Membahas Adanya ketidaktepatan dalam memberikan nilai kepada karyawan berdampak pada hasil keputusan yang diberikan kurang tepat. Hasil yang terdapat pada penelitian tersebut berupa berbasis dekstop dan Menghasilkan sebuah alternatif solusi karyawan terbaik dengan memasukkan beberapa alternatif karyawan dan penilaian-penilaian dari beberapa kriteria yaitu : presensi, perilaku, penampilan dan atribut, yang dimana kriteria tersebut sudah ditentukan oleh pihak pengambil keputusan (Eko Wiyono \& Latipah, 2017).

Pada penelitian sebelumnya yang berjudul Sistem Penunjang Keputusan Penerima Kartu Indonesia Pintar Menggunakan Metode Simple Additive Weighting (SAW). Membahas sebuah sistem penerimaan kartu 
Indonesia pintar Hasil yang terdapat pada penelitian tersebut adalah menggunakan metode SAW sangat tepat untuk menyelesaikan masalah yang memiliki banyak data sehingga sulit untuk menentukan keputusan untuk kartu Indonesia pintar. Pada penelitian tersebut terdapat beberapa variabel kriteria yang digunakan untuk memusutkan penerima kartu Indonesia pintar yaitu : jumlah tanggungan orang tua, jumlah penghasilan orang tua, pekerjaan orang tua, kelas, dan keadaan orang tua. (Wahyudi et al., 2019).

Pada penelitian sebelumnya yang berjudul Sistem Pendukung Keputusan Kenaikan Jabatan Fungsional dan Pangkat Dosen. Membahas sebuah sistem untuk menentukan dosen yang berhak untuk mendapatkan jabatan yang layak sesuai dengan kinerjanya. Masalah yang dihadapi berupa pemantauan jenjang kenaikan jabatan fungsional dan pangkat dosen di masingmasing di Peguruan Tingginya, jenjang kenaikan jabatan tersebut memiliki variabel kriteria yang dinilai yaitu : jenjang jabatan, jenjang pangkat/golongan, angka kredit, dimana dosen harus memenuhi kriteria yang telah ditentukan. Untuk itu diperlukan sistem tersebut karena masih banyak dosen yang lebih dari 2 tahun belum mengajukan kenaikan jabatan fungsional dan pangkatnya (Hartini \& Tan, 2018)

Pada penelitian sebelumnya yang berjudul Sistem Pendukung Keputusan Pemilihan Sekolah SMK Swasta Penerima Dana Bantuan Menerapkan Metode Simple Additive Weighting (SAW). Membahas sebuah sistem untuk pemilihan sekolah swasta untuk penerima dana bantuan. Dan menghasilkan hasil yang akurat untuk memilih dari beberapa sebuah sekolah SMK swasta dari variabel kriteria yang telah ditentukan seperti: prestasi siswa, rata rata penghasilan orang tua, mengikuti peraturan pemerintah, tingkat keaktifan siswa. Sehingga tidak terjadi kesalahan dalam pengambilan keputusan untuk penerimaan bantuan dana. (Hutahaean \& Badaruddin, 2020).

Metode Simple Additive Weighting (SAW) merupakan suatu cara perhitungan penjumlahan pembobotan. Mencari sebuah penjumlahan terbobot yang didapat dari rating kinerja pada setiap alternatif di semua atribut hal tersebut merupakan sebuah konsep dari metode SAW (Kusumawardani et al., 2019). Pada metode SAW, rating atau nilai tiap atribut harus sudah melewati proses normalisasi. Normalisasi metrik keputusan $(\mathrm{X})$ ke suatu skala yang nantinya bisa dilakukan proses perbandingan pada semua nilai alternatif yang ada
Langkah-langkah metode SAW (Hutahaean \& Badaruddin, 2020):

1. Menentukan kriteria-kriteria pada pengambilan keputusan, hal tersebut biasa dinamankan $\mathrm{Ci}$.

2. Menentukan rating kecocokan terhadap setiap alternatif dan setiap kriteria.

3. Membuat matriks keputusan berdasarkan kriteria (Ci), kemudian melakukan normalisasi matriks berdasarkan persamaan yang disesuaikan dengan jenis atribut (atribut keuntungan ataupun atribut biaya) sehingga diperoleh matriks ternormalisasi R.

4. Mendapatkan hasil akhir berupa perangkingan yang diperoleh dari sebuah penjumlahan dari perkalian matrik ternormalisasi dan juga dengan vektor berbobot sehingga mendapatkan nilai terbesar yang dijadikan sebagai nilai alternatif. Pada hal tersebut merupakan sebuah hasil perkalian dari bobot preferensi yang disimbolkan dengan (W) dengan kolom pada matriks ternormalisasi tiap satu baris dengan sesuai alternatif yang diberikan. Berikut rumus untuk melakukan perhitungan normalisasi pada persamaan dibawah ini

$x_{i j}=\frac{x_{i j}}{\operatorname{Max} x_{i j}}$ (1) Apabila $\mathrm{j}$ adalah atribut keuntungan Dimana

$\mathrm{r}_{\mathrm{ij}} \quad=$ rating kinerja ternormalisasi

Max $_{i j}=$ nilai maksimum dari setiap baris dan kolom

$\operatorname{Min}_{\mathrm{ij}}=$ nilai minimum dari setiap baris dan kolom

$\mathrm{X}_{\mathrm{ij}} \quad=$ baris dan kolom dari matriks

Nilai preferensi untuk tiap alternatif (Vi) diberikan sebagai :

$V_{i}=\sum_{j}^{n}=1 w_{j} r_{i j}$

Dimana :

$\mathrm{V}_{\mathrm{i}} \quad=$ Nilai akhir dari alternatif

$\mathrm{w}_{\mathrm{j}} \quad=$ Bobot yang telah ditentukan

$\mathrm{rij}_{\mathrm{ij}} \quad=$ Normlisasi matrix

Sebuah sistem informasi berbasis komputer termasuk sistem berbasis pengetahuan (manajemen pengetahuan) yang digunakan untuk mendukung dalam pengambilan keputusan pada suatu organisasi atau perusahaan disebut sistem pendukung keputusan. Dapat juga dikatakan sebagai sistem komputer yang mengolah data menjadi informasi untuk mengambil keputusan dari masalah semi-terstruktur yang spesifik (Sistem, 2017). Komponen pada sistem pengambilan keputusan adalah sebagai berikut (Hartini \& Tan, 2018): (a) Data Management : Merupakan hal yang berkaitan terkait database yang mengandung sebuah data yang relevan dan 
diatur oleh sistem. (b) Model Management : Merupakan hal yang berkaitan pada sebuah paket perangkat lunak yang memasukkan model-model finansial, statistik, ilmu manajemen, atau model kuantitatif yang mempunyai kemampuan analisis sistem dan management software. (c) Communication : Sebuah media interaksi antara sistem dengan pengguna, yang dimana antara pengguna dan sistem dapat berkomunikasi dan memberikan sebuah perintah pada sistem pendukung keputusan. (d) Knowledge Management : Sebuah subsistem yang mendukung subsistem lain dan dapat bertindak sebagai komponen yang berdiri sendiri.

\section{Metode Penelitian}

1. Tahapan Penelitian

Pada penelitian ini penulis menggunakan metode Waterfall untuk menyelesaikan masalah saat menggunakan algoritma SAW yang dimana metode waterfall tersebut merupakan pengembangan sebuah software memiliki sebuah tahapan seperti air terjun, dan tahapan per tahapan harus diselesaikan agar bisa dilanjutkan ke dalam tahapan berikutnya (Adianto et al., 2017).

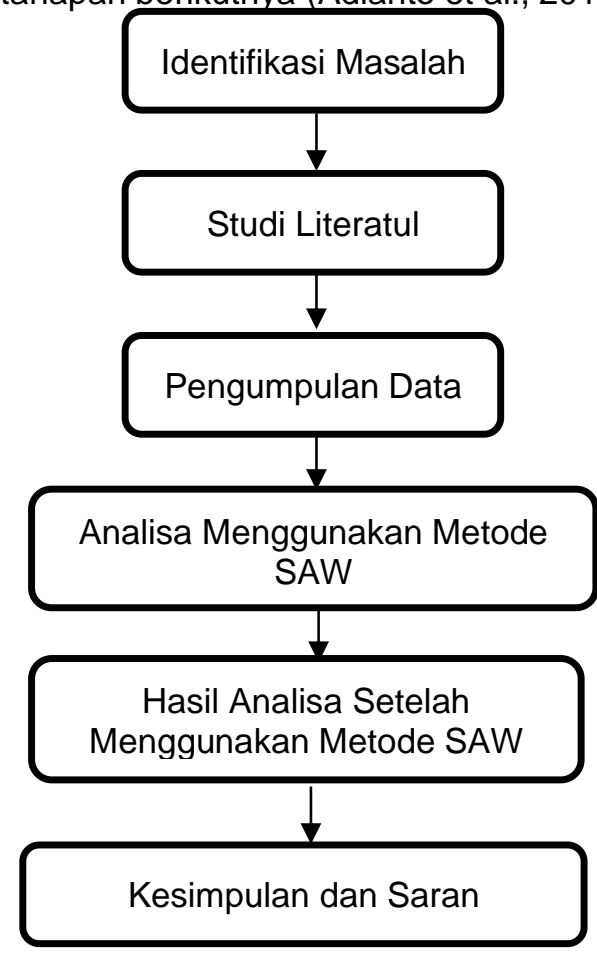

Sumber : (Somya \& Wahyudi, 2020)

Gambar 1. Tahapan Penelitian

Pada tahap penelitian ini dapat dijelaskan sebagai berikut :

1. Identifikasi Masalah, adalah mengidentifikasi sebuah permasalahan yang di satukan dalam rumusan masalah pada PT SCMedia (Somya \& Wahyudi, 2020).
2. Studi Literatul, merupakan sebuah pembelajaran untuk memahami teori teori yang mendukung sebuah sistem pengambilan keputusan (Wahyudi et al., 2019).

3. Pengumpulan Data, merupakan pengumpulan data yang dilakukan dengan 2 cara yaitu dengan cara wawancara dan observasi kepada pihak PT SCMedia (Wahyudi et al., 2019).

4. Analisa Mengunakan Metode SAW, merupakan sebuah Analisa yang menggunakan jenis penelitian kuantitatif (Somya \& Wahyudi, 2020).

5. Hasil Analisa Setelah Menggunakan Metode SAW, merupakan tahapan setelah Analisa menggunakan metode SAW (Wahyudi et al., 2019).

6. Kesimpulan dan Saran, tahapan akhir dari proses penelitian dengan menyimpulkan penelitian dari awal hingga hasilnya (Wahyudi et al., 2019).

2. Perancangan Sistem

Perancangan sistem ini dibangun menggunakan Unified Modeling Language (UML) yang dimana digunakan untuk menggambarkan sebuah sistem dalam bentuk diagram. Bentuk diagramnya tersebut seperti : Activity Diagram, Usecase Diagram (Susanto \& Eriana, 2020).

Activity Diagram merupakan sebuah aliran kerja pada sebuah sistem yang akan dibangun. yang menunjukkan aliran atau aluran dalam suatu program. Karena activity diagram berguna untuk mempermudah untuk mengetahui arah dari perilaku sistem yang dibangun(Somya \& Wahyudi, 2020).

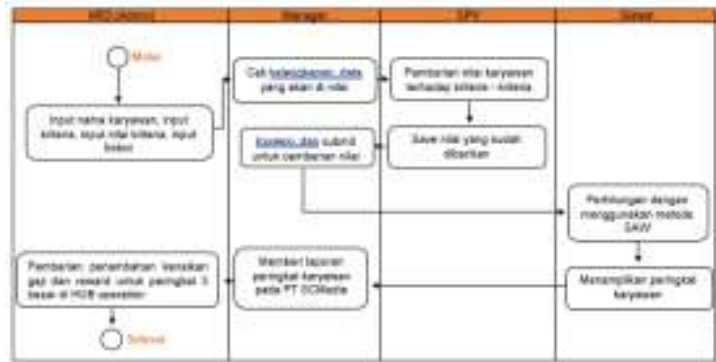

Sumber : (Somya \& Wahyudi, 2020)

Gambar 2. Activity Diagram Proses

Pemilihan Karyawan Teladan

Pada gambar 2 menjelaskan activity diagram proses pemilihan karyawan teladan untuk mendapatkan penambahan kenaikan gaji dan sebuah reward di PT Semesta Citra Media. Proses ini dimulai dengan HRD melakukan penginputan karyawan dan melakukan penginputan sebuah kriteria beserta nilainya, dan melakukan penginputan bobot dari sebuah kriteria tersebut. Kemudian, HRD menginfokan kepada manager bahwasanya sudah dilakukan 
penginputan untuk penilaian. Dan manager melakukan pengecekan kelengkapan data untuk karyawan HUB Operation. Kemudian, Supervisi bagian Helpdesk, NOC, dan SLA melakukan penilaian terhadap bawahannya kemudian melakukan save atau penyimpanan. Kemudian manager melakukan pemeriksaan terhadap nilai yang diberikan, dan melakukan submit nilai tersebut. Kemudian akan dilakukan perhitungan metode SAW agar sebuah perhitungan tepat. Kemudian akan mendapatkan hasil dari sebuah perhitungan metode tersebut yang berupa sebuah ranked dari 1 hingga akhir. Kemudian manager akan mengirimkan hasil karyawan teladan tersebut ke HRD untuk melakukan penambahan kenaikan gaji dan sebuah reward. Usecase diagram merupakan sebuah diagram yang menjelaskan fungsional terhadap aktor aktor pada sistem yang dibangun (Sistem, 2017).

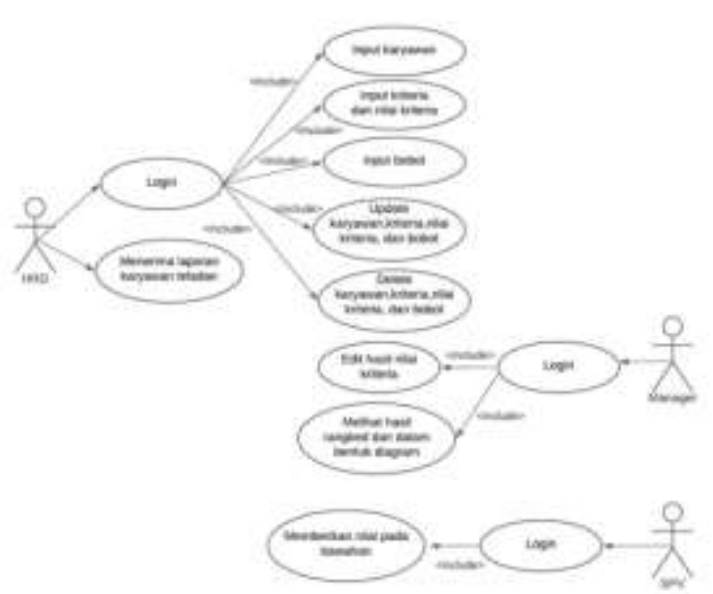

Sumber : (Alamsyah, 2020)

Gambar 3. Usecase Diagram

Pada gambar 3 menjelaskan usecase diagram dari sistem, Aktor yang terpenting dalam sistem ini adalah HRD, karena dapat menginput karyawan, menginput, update dan delete kriteria dan nilai kriteria karyawan. Dan HRD dapat melihat data nilai perhitungan yang sudah dinilai dari supervisor dan sudah di periksa oleh manager HUB Operation. Dan untuk actor Manager, memiliki peran sama seperti HRD namun manager tidak memiliki akses untuk menginput, delete, dan update nilai kriteria dan nilai bobot tersebut. Dan untuk aktor SPV hanya memiliki akses untuk menilai anak anak bawahannya.

\section{Indikator Dalam Penentuan Bedasarkan Per Kriteria}

Pada hal ini akan melakukan indikator kriteria yang dinilai, yang dimana kriteria tersebut didapatkan dari data perusahaan PT SCMedia a. Prestasi Kerja

Tabel 1. Kriteria Prestasi Kerja

\begin{tabular}{|c|c|}
\hline \multirow[b]{2}{*}{ Kriteria } & \\
\hline & \begin{tabular}{l}
\multicolumn{1}{c}{ Keterangan } \\
Pengertian terhadap \\
pekerjaan \\
Kecepatan melaksanakan \\
pekerjaan
\end{tabular} \\
\hline $\begin{array}{c}\text { Prestasi } \\
\text { Kerja }\end{array}$ & $\begin{array}{l}\text { Ketelitian melaksanakan } \\
\text { pekerjaan } \\
\text { Inisiatif dalam memecahkan } \\
\text { masalah pekerjaan } \\
\text { Kreativitas dalam } \\
\text { melaksanakan pekerjaan. }\end{array}$ \\
\hline \multicolumn{2}{|c|}{$\begin{array}{l}\text { Sumber : (Wahyudi et al., 2019) } \\
\text { Displin Kerja } \\
\quad \text { Tabel 2. Kriteria Displin Kerja }\end{array}$} \\
\hline Kriteria & Keterangan \\
\hline $\begin{array}{l}\text { Displin } \\
\text { Kerja }\end{array}$ & $\begin{array}{l}\text { Kepatuhan terhadap Tata } \\
\text { Tertib. } \\
\text { Kepatuhan terhadap perintah } \\
\text { kerja. } \\
\text { Kepatuhan terhadap } \\
\text { keamanan \& keselamatan } \\
\text { kerja }\end{array}$ \\
\hline
\end{tabular}

Sumber : (Wahyudi et al., 2019)

c. Tanggung Jawab

Tabel 3. Kriteria Tanggung Jawab Kerja

\begin{tabular}{cl}
\hline Kriteria & \multicolumn{1}{c}{ Keterangan } \\
\hline & Minat pada pekerjaan \\
& Semangat kerja \\
& Kepercayaan diri \\
dalam melaksanakan \\
Tanggung & pekerjaan. \\
Jawab & Tanggung jawab \\
& untuk melaksanakan \\
& pekerjaan. \\
& Kemauan untuk \\
& meningkatkan \\
& prestasi kerja.
\end{tabular}

Sumber : (Wahyudi et al., 2019)

d. Komunikasi

Tabel 4. Kriteria Komunikasi

\begin{tabular}{cl}
\hline Kriteria & \multicolumn{1}{c}{ Keterangan } \\
\hline Komunikasi & $\begin{array}{l}\text { Hubungan dengan atasan } \\
\text { Hubungan dengan sesama / } \\
\text { rekan }\end{array}$ \\
\hline
\end{tabular}

Sumber : (Wahyudi et al., 2019)

e. Kepribadian

Tabel 5. Kriteria Kepribadian

\begin{tabular}{|c|c|}
\hline Kriteria & Keterangan \\
\hline \multirow{5}{*}{ Kepribadian } & Kejujuran \\
\hline & Kerapihan Kerja \\
\hline & Kemampuan \\
\hline & mengendalikan diri \\
\hline & $\begin{array}{l}\text { Perilaku sehari-hari. } \\
\text { Kejujuran }\end{array}$ \\
\hline
\end{tabular}

Sumber : (Wahyudi et al., 2019) 
4. Penentuan Bobot Preferensi (W) dan Bobot Per Kriteria

Bobot prefrensi merupakan sebuah nilai yang memiliki tingkat kepentingan terhadap kriteria. Bobot tersebut berpengaruh terhadap perhitungan rangking pada metode SAW. Karena bobot preferensi tersebut saling berhubungan dengan nilai preferensi. Berikut bobot preferensi seperti tabel 6 yang didapat dari data perusahaan dan tabel 7 bobot dari per kriteria

Tabel 6. Bobot Preferensi

\begin{tabular}{llc}
\hline Kriteria & Keterangan & Bobot \\
\hline C1 & Prestasi Kerja & 30 \\
C2 & Displin Kerja & 30 \\
C3 & Tanggung Jawab & 20 \\
C4 & Komunikasi & 10 \\
C5 & Kepribadian & 10 \\
\hline Sumber : (Kusumawardani et al., 2019)
\end{tabular}

Tabel 7. Bobot Per Kriteria

\begin{tabular}{ccl}
\hline No & Bobot & \multicolumn{1}{c}{ Keterangan } \\
\hline 1 & TT & Tidak Tertinjau \\
2 & 3 & Jauh Dari Persyaratan \\
3 & 4 & Sangat Kurang \\
4 & 5 & Kurang \\
5 & 6 & Sedang \\
6 & 7 & Cukup \\
7 & 8 & Baik \\
8 & 9 & Sangat Baik \\
9 & 10 & Sempurna \\
\hline \multicolumn{3}{l}{ Sumber : (Kusumawardani et al., 2019) }
\end{tabular}

5. Teknik Analisis Data Dengan Metode SAW Analisis data menggunakan metode SAW merupakan analisis data pada kasus yang dihadapi, dimana pada metode SAW terdapat 4 tahapan yang akan dilakukan, seperti :

a. Pengumpulan kriteria

Kriteria yang didapat merupakah data dari perusahaan PT SCMedia

Tabel 8. Pengumpulan Kriteria

\begin{tabular}{ll}
\hline Kriteria & \multicolumn{1}{c}{ Keterangan } \\
\hline C1 & Prestasi Kerja \\
C2 & Displin Kerja \\
C3 & Tanggung Jawab \\
C4 & Komunikasi \\
C5 & Kepribadian \\
\hline
\end{tabular}

Sumber : (Kusumawardani et al., 2019)

b. Menentukan rating kecocokan terhadap setiap alternatif dari setiap kriteria

Pada tahapan ini alternatif 1 - 40 merupakan nama karyawan pada SCMedia. dimana alternatif tersebut berikan nilai dari setiap kriteria
Tabel 9. Rating Kecocokan Kriteria

\begin{tabular}{|c|c|c|c|c|c|}
\hline \multirow[b]{2}{*}{$\begin{array}{c}\text { Altern } \\
\text { atif }\end{array}$} & \multicolumn{5}{|c|}{ Kriteria } \\
\hline & C1 & C2 & $\mathrm{C} 3$ & C4 & C5 \\
\hline $\mathrm{A} 1$ & 7.80 & 7.67 & 7.80 & 8.00 & 8.00 \\
\hline A2 & 7.60 & 8.00 & 7.60 & 8.00 & 7.25 \\
\hline A3 & 7.00 & 8.00 & 7.40 & 8.00 & 7.75 \\
\hline A4 & 7.80 & 8.00 & 7.60 & 8.00 & 7.50 \\
\hline A5 & 8.40 & 7.67 & 7.80 & 8.00 & 8.00 \\
\hline A6 & 7.40 & 8.00 & 7.40 & 8.50 & 7.75 \\
\hline A7 & 8.20 & 7.67 & 8.00 & 8.50 & 7.50 \\
\hline A8 & 6.60 & 7.33 & 6.80 & 8.00 & 7.50 \\
\hline A9 & 7.60 & 7.33 & 8.00 & 8.00 & 7.25 \\
\hline A10 & 8.20 & 8.33 & 8.00 & 8.00 & 7.75 \\
\hline A11 & 7.80 & 7.67 & 7.60 & 8.00 & 7.75 \\
\hline A12 & 8.00 & 7.67 & 7.80 & 9.00 & 7.75 \\
\hline A13 & 7.60 & 7.67 & 7.80 & 8.50 & 7.75 \\
\hline A14 & 8.00 & 8.00 & 7.80 & 8.50 & 7.75 \\
\hline A15 & 7.20 & 8.00 & 7.60 & 8.00 & 7.75 \\
\hline A16 & 8.00 & 7.67 & 7.80 & 7.50 & 7.75 \\
\hline A17 & 7.80 & 8.33 & 7.60 & 7.50 & 7.75 \\
\hline A18 & 8.20 & 8.3 & 8.40 & 8.00 & 7.75 \\
\hline A19 & 7.20 & 7.00 & 7.60 & 8.00 & 7.50 \\
\hline A20 & 7.60 & 7.67 & 7.40 & 8.00 & 7.50 \\
\hline A21 & 7.20 & 7.33 & 8.00 & 8.00 & 7.25 \\
\hline A22 & 7.40 & 7.67 & 7.60 & 6.50 & 7.25 \\
\hline A23 & 7.40 & 8.33 & 7.80 & 8.00 & 7.50 \\
\hline A24 & 7.60 & 8.00 & 7.80 & 8.00 & 7.75 \\
\hline A25 & 7.60 & 8.00 & 7.80 & 8.00 & 7.75 \\
\hline A26 & 8.00 & 7.67 & 8.00 & 8.00 & 7.75 \\
\hline A27 & 7.80 & 7.67 & 8.20 & 8.00 & 7.75 \\
\hline A28 & 7.80 & 8.00 & 7.80 & 8.00 & 8.00 \\
\hline A29 & 7.60 & 8.00 & 7.80 & 8.00 & 8.00 \\
\hline A30 & 8.00 & 7.67 & 7.80 & 8.00 & 8.00 \\
\hline A31 & 7.60 & 8.00 & 7.80 & 8.00 & 8.00 \\
\hline A32 & 7.60 & 8.00 & 8.00 & 8.00 & 8.00 \\
\hline A33 & 8.00 & 8.00 & 7.80 & 8.00 & 8.00 \\
\hline A34 & 8.00 & 8.00 & 7.80 & 8.50 & 8.00 \\
\hline A35 & 7.80 & 7.67 & 8.00 & 8.50 & 8.00 \\
\hline A36 & 7.80 & 8.00 & 7.80 & 8.00 & 8.00 \\
\hline A37 & 7.80 & 8.00 & 7.80 & 7.50 & 8.00 \\
\hline A38 & 7.60 & 8.00 & 8.00 & 8.00 & 8.00 \\
\hline A39 & 7.60 & 8.33 & 7.80 & 7.50 & 8.00 \\
\hline A40 & 7.60 & 8.00 & 8.00 & 8.00 & 8.00 \\
\hline
\end{tabular}


Nilai dari rating kecocokan dibuat kedalam bentuk matriks (Manajemen et al., 2017). Berikut matriks keputusan yang penulis sajikan di lampiran 1.

d. Melakukan Normalisasi Matriks

Normalisasi matriks merupakan persamaan yang disesuaikan dengan jenis atribut

Tabel 10. Tabel Normalisasi Matriks

\begin{tabular}{lcc}
\hline \multicolumn{1}{c}{ Kriteria } & Benefit & Cost \\
\hline Prestasi Kerja & $\checkmark$ & - \\
Displin Kerja & $\checkmark$ & - \\
Tanggung Jawab & $\checkmark$ & - \\
Komunikasi & $\checkmark$ & - \\
Kepribadian & $\checkmark$ & - \\
\hline
\end{tabular}

Sumber : (Saefulloh et al., 2017)

Karena semua kriteria merupakan atribut benefit maka persamaan yang digunakan berupa MAX, dengan persamaan berikut

$$
x_{i j}=\frac{x_{i j}}{\operatorname{Max} x_{i j}}
$$

Contoh dar hasil persamaan tersebut maka nilai $\mathrm{R}$ diperoleh seperti :

$X_{11}=7,80 / 8,40=0,929 ; X_{12}=7,67 / 8,33=$ 0,$921 ; X_{13}=8,00 / 8,40=0,929 ; X_{14}=8,00 /$ $9,00=0,889 ; X_{15}=8,00 / 8,00=1,000$ dan seterusnya perhitungan mengikuti seperti diatas. Maka dari contoh perhitungan pada persaman tersebut maka terjadi normalisasi seperti pada lampiran 2.

\section{e. Menghitung nilai preferensi}

Menghitung nilai preferensi merupakan sebuah nilai yang diperoleh dari perhitungan nilai $R$ yang akan dikalikan oleh bobot preferensi yang telah ditentukan (Yogi Hermawan et al., 2019). Berikut persamaan untuk menghitung nilai preferensi :

$$
V_{i}=\sum_{j}^{n}=1 w_{j} r_{i j}
$$

Dari persaman tersebut dengan bobot preferensi yang telah ditentukan sebagai berikut :

Tabel 11. Bobot Preferensi

\begin{tabular}{llc}
\hline Kriteria & \multicolumn{1}{c}{ Keterangan } & Bobot \\
\hline C1 & Prestasi Kerja & 30 \\
C2 & Displin Kerja & 30 \\
C3 & Tanggung Jawab & 20 \\
C4 & Komunikasi & 10 \\
C5 & Kepribadian & 10 \\
\hline
\end{tabular}

Sumber : (Kusumawardani et al., 2019)

Hasil yang didapakan dengan menggunakan persamaan tersebut adalah : $\mathrm{A} 1=(0,929 \times 30)+(0,921 \times 30)+(0,929 \times 20)$ $+(0,889 \times 10)+(1,000 \times 10)=92,941$
$\mathrm{A} 2=(0,905 \times 30)+(0,960 \times 30)+(0,905 \times 20)$ $+(0,889 \times 10)+0,906 \times 10=92,001$

$\mathrm{A} 3=(0,883 \times 30)+(0,960 \times 30)+(0,881 \times 20)$ $+(0,889 \times 10)+(0,969 \times 10)=90,007$ $\mathrm{A} 4=(0,929 \times 30)+(0,960 \times 30)+(0,905 \times 20)$ $+(0,889 \times 10)+(0,938 \times 10)=93,028$

$\mathrm{A} 5=(1,000 \times 30)+(0,921 \times 30)+(0,929 \times 20)$ $+(0,889 \times 10)+(1,000 \times 10)=95,083$ $A 6=(0,881 \times 30)+(0,960 \times 30)+(0,881 \times 20)$ $+(0,944 \times 10)+(0,969 \times 10)=91,991$ $A 7=(0,976 \times 30)+(0,921 \times 30)+(0,952 \times 20)$ $+(0,944 \times 10)+(0,938 \times 10)=94,776$ $A 8=(0,786 \times 30)+(0,880 \times 30)+(0,810 \times 20)$ $+(0,889 \times 10)+(0,938 \times 10)=84,424$ $A 9=(0,905 \times 30)+(0,880 \times 30)+(0,952 \times 20)$ $+(0,889 \times 10)+(0,906 \times 10)=90,540$ $\mathrm{A} 10=(0,976 \times 30)+(1,000 \times 30)+(0,952 \times 20)$ $+(0,889 \times 10)+(0,969 \times 10)=96,910$ $A 11=(0,929 \times 30)+(0,921 \times 30)+(0,905 \times 20)$ $+(0,889 \times 10)+(0,969 \times 10)=92,152$ $\mathrm{A} 12=(0,952 \times 30)+(0,921 \times 30)+(0,929 \times 20)$ $+(1,000 \times 10)+(0,969 \times 10)=94,453$ $\mathrm{A} 13=(0,905 \times 30)+(0,921 \times 30)+(0,929 \times 20)$ $+(0,944 \times 10)+(0,969 \times 10)=92,469$ $\mathrm{A} 14=(0,952 \times 30)+(0,960 \times 30)+(0,929 \times 20)$ $+(0,944 \times 10)+(0,969 \times 10)=95,086$ $\mathrm{A} 15=(0,857 \times 30)+(0,960 \times 30)+(0,905 \times 20)$ $+(0,889 \times 10)+(0,969 \times 10)=91,197$ $\mathrm{A} 16=(0,952 \times 30)+(0,921 \times 30)+(0,929 \times 20)$ $+(0,833 \times 10)+(0,969 \times 10)=92,787$ $\mathrm{A} 17=(0,929 \times 30)+(1,000 \times 30)+(0,905 \times 20)$ $+(0,833 \times 10)+(0,969 \times 10)=93,973$ $\mathrm{A} 18=(0,976 \times 30)+(1,000 \times 30)+(1,000 \times 20)$ $+(0,889 \times 10)+(0,969 \times 10)=97,862$ $A 19=(0,857 \times 30)+(0,840 \times 30)+(0,905 \times 20)$ $+(0,889 \times 10)+(0,938 \times 10)=87,283$ $\mathrm{A} 20=(0,905 \times 30)+(0,921 \times 30)+(0,881 \times 20)$ $+(0,889 \times 10)+(0,938 \times 10)=90,649$ $\mathrm{A} 21=(0,857 \times 30)+(0,880 \times 30)+(0,952 \times 20)$ $+(0,889 \times 10)+(0,906 \times 10)=89,112$ A22 $=(0,881 \times 30)+(0,921 \times 30)+(0,905 \times 20)$ $+(0,722 \times 10)+(0,906 \times 10)=88,432$ $A 23=(0,881 \times 30)+(1,000 \times 30)+(0,929 \times 20)$ $+(0,889 \times 10)+(0,938 \times 10)=93,264$ A24 $=(0,905 \times 30)+(0,960 \times 30)+(0,929 \times 20)$ $+(0,889 \times 10)+(0,969 \times 10)=93,102$ $\mathrm{A} 25=(0,905 \times 30)+(0,960 \times 30)+(0,929 \times 20)$ $+(0,889 \times 10)+(0,969 \times 10)=93,102$ $\mathrm{A} 26=(0,952 \times 30)+(0,921 \times 30)+(0,952 \times 20)$ $+(0,889 \times 10)+(0,969 \times 10)=93,818$ $\mathrm{A} 27=(0,929 \times 30)+(0,921 \times 30)+(0,976 \times 20)$ $+(0,889 \times 10)+(0,969 \times 10)=93,580$ A28 $=(0,929 \times 30)+(0,960 \times 30)+(0,929 \times 20)$ $+(0,889 \times 10)+(1,000 \times 10)=94,129$ $\mathrm{A} 29=(0,905 \times 30)+(0,960 \times 30)+(0,929 \times 20)$ $+(0,889 \times 10)+(1,000 \times 10)=93,415$ $\mathrm{A} 30=(0,952 \times 30)+(0,921 \times 30)+(0,929 \times 20)$ $+(0,889 \times 10)+(1,000 \times 10)=93,655$ $\mathrm{A} 31=(0,905 \times 30)+(0,960 \times 30)+(0,929 \times 20)$ $+(0,889 \times 10)+(1,000 \times 10)=93,415$ 
$\mathrm{A} 32=(0,905 \times 30)+(0,960 \times 30)+(0,952 \times 20)$

$+(0,889 \times 10)+(1,000 \times 10)=93,891$

$\mathrm{A} 33=(0,952 \times 30)+(0,960 \times 30)+(0,929 \times 20)$

$+(0,889 \times 10)+(1,000 \times 10)=94,843$

$\mathrm{A} 34=(0,952 \times 30)+(0,960 \times 30)+(0,929 \times 20)$

$+(0,944 \times 10)+(1,000 \times 10)=95,399$

A35 $=(0,929 \times 30)+(0,921 \times 30)+(0,952 \times 20)$

$+(0,944 \times 10)+(1,000 \times 10)=93,972$

$\mathrm{A} 36=(0,929 \times 30)+(0,960 \times 30)+(0,929 \times 20)$

$+(0,889 \times 10)+(1,000 \times 10)=94,129$

A37 $=(0,929 \times 30)+(0,960 \times 30)+(0,929 \times 20)$

$+(0,833 \times 10)+(1,000 \times 10)=93,573$

$\mathrm{A} 38=(0,905 \times 30)+(0,960 \times 30)+(0,952 \times 20)$

$+(0,889 \times 10)+(1,000 \times 10)=93,891$

$\mathrm{A} 39=(0,905 \times 30)+(1,000 \times 30)+(0,929 \times 20)$

$+(0,833 \times 10)+(1,000 \times 10)=94,048$

$\mathrm{A} 40=(0,905 \times 30)+(0,960 \times 30)+(0,952 \times 20)$

$+(0,889 \times 10)+(1,000 \times 10)=93,891$

f. Hasil Peringkat Karyawan Teladan

Tabel 13. Hasil Peringkat Karyawan Teladan

\begin{tabular}{|c|c|c|c|}
\hline Karyawan & Alternatif & Hasil & Peringkat \\
\hline $\begin{array}{l}\text { Wisnu } \\
\text { Pratama }\end{array}$ & A18 & 97,862 & 1 \\
\hline $\begin{array}{l}\text { Wahyu } \\
\text { Ningsih }\end{array}$ & A10 & 96,910 & 2 \\
\hline $\begin{array}{l}\text { Adam } \\
\text { Ramadhan }\end{array}$ & A34 & 95,399 & 3 \\
\hline Muslikin & A14 & 95,086 & 4 \\
\hline Aris Yuliono & A5 & 95,083 & 5 \\
\hline $\begin{array}{l}\text { Antonius } \\
\text { Harry }\end{array}$ & A33 & 94,843 & 6 \\
\hline $\begin{array}{l}\text { Achmad } \\
\text { Robi }\end{array}$ & A7 & 94,776 & 7 \\
\hline $\begin{array}{l}\text { Reza } \\
\text { Mubarok }\end{array}$ & A12 & 94,453 & 8 \\
\hline Eldhi F & A28 & 94,129 & 9 \\
\hline Chintya Eka & A36 & 94,129 & 10 \\
\hline Febi Arlita & A39 & 94,048 & 11 \\
\hline $\begin{array}{l}\text { Ajeng Eka } \\
\text { Putri }\end{array}$ & A17 & 93,973 & 12 \\
\hline $\begin{array}{l}\text { Doni } \\
\text { Rafiandi }\end{array}$ & A35 & 93,972 & 13 \\
\hline $\begin{array}{l}\text { Imam Fabiq } \\
\text { Aldimas }\end{array}$ & A32 & 93,891 & 14 \\
\hline $\begin{array}{l}\text { Denny } \\
\text { Chanditya }\end{array}$ & A38 & 93,891 & 15 \\
\hline Anissa & A40 & 93,891 & 16 \\
\hline Asraind & A26 & 93,818 & 17 \\
\hline Novi Eko & A30 & 93,655 & 18 \\
\hline $\begin{array}{l}\text { Achmad } \\
\text { Syah R }\end{array}$ & A27 & 93,580 & 19 \\
\hline Putri & A37 & 93,573 & 20 \\
\hline Rizko & A29 & 93,415 & 21 \\
\hline $\begin{array}{l}\text { Andi Imam } \\
\text { Dwi Rizki }\end{array}$ & A31 & 93,415 & 22 \\
\hline
\end{tabular}

\begin{tabular}{|c|c|c|c|}
\hline $\begin{array}{l}\text { M. Ashari } \\
\text { Arfan Salim }\end{array}$ & A23 & 93,264 & 23 \\
\hline \multirow{2}{*}{$\begin{array}{l}\text { Wachid } \\
\text { Joansyah } \\
\text { Dimas }\end{array}$} & A24 & 93,102 & 24 \\
\hline & A25 & 93,102 & 25 \\
\hline Firdaus & A4 & 93,028 & 26 \\
\hline $\begin{array}{l}\text { Muhamad } \\
\text { Rizky Fajar }\end{array}$ & $\mathrm{A} 1$ & 92,941 & 27 \\
\hline $\begin{array}{l}\text { Fajri } \\
\text { Tanjung }\end{array}$ & A16 & 92,787 & 28 \\
\hline \multicolumn{4}{|l|}{$\begin{array}{l}\text { Muchtiarizky } \\
\text { Anugrah }\end{array}$} \\
\hline \multicolumn{4}{|l|}{ Rasyid } \\
\hline \multicolumn{4}{|l|}{$\begin{array}{l}\text { Bagus } \\
\text { Triawan }\end{array}$} \\
\hline \multicolumn{4}{|l|}{ Nur Said } \\
\hline \multicolumn{4}{|l|}{ Andriyadi } \\
\hline \multicolumn{4}{|l|}{$\begin{array}{l}\text { Muhamad } \\
\text { Ramdan }\end{array}$} \\
\hline Ahmad & A9 & 90,540 & 35 \\
\hline $\begin{array}{l}\text { Teguh } \\
\text { Cahyadi } \\
\text { Wahyu }\end{array}$ & A3 & 90,007 & 36 \\
\hline & $\mathrm{A} 21$ & 89,112 & 37 \\
\hline $\begin{array}{l}\text { Ridho } \\
\text { Wardhana }\end{array}$ & A22 & 88,432 & 38 \\
\hline & A19 & 87,283 & 39 \\
\hline Yudhies Eka & A8 & 84,424 & 40 \\
\hline \multicolumn{4}{|c|}{$\begin{array}{l}\text { Sumber : (Sistem, 2017) } \\
\text { Dari hasil perangkingan tersebut, Wisnu } \\
\text { pratama dengan alternatif A18, Aris Yuliono } \\
\text { dengan alternatif A5, dan Wahyuningsih } \\
\text { dengan alternatif A10 ditentukan sebagai } \\
\text { karyawan teladan yang pantas untuk } \\
\text { mendapatkan penambahan kenaikan gaji dan } \\
\text { reward berupa sertifikat dan cuti yang diberikan } \\
\text { oleh manager dan hrd. Dan untuk peringkat 4- } \\
40 \text { tetap mendapatkan kenaikan gaji dengan } \\
\text { standarnya tidak ada penambahan } \\
\text { (Susliansyah et al., 2019). }\end{array}$} \\
\hline
\end{tabular}

\section{Hasil dan Pembahasan}

Pada bagian ini, dijelaskan hasil dan pembahasan tentang proses pembuatan sistem pendukung keputusan karyawan teladan menggunakan metode SAW dan akan menjelaskan terkait design user interface dan pengujian sistem.

\section{Halaman Antarmuka Login}

Pada halaman ini akan menampilkan tampilan login sebelum memasuki sebuah 
sistem pengambilan keputusan tersebut. Terdapat beberapa pengguna login seperti, SPV, Manager. Pengguna login tersebut harus didaftarkan terlebih dahulu oleh HRD atau admin.

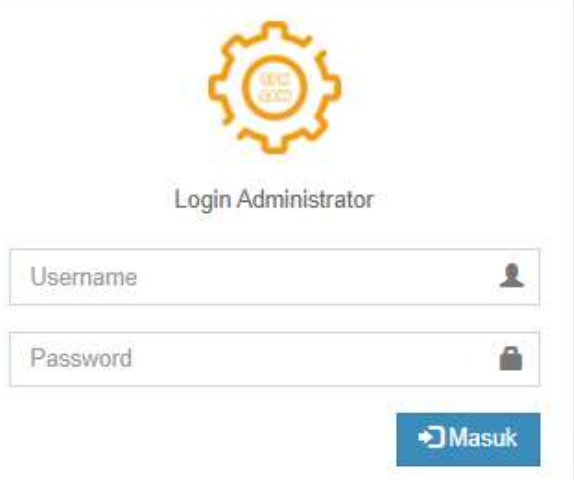

Sumber :(Alamsyah, 2020)

\section{Halaman Dasboard}

Gambar 4. Halaman Login

Pada halaman ini, menampilkan sebuah dashboard pada sebuah sistem. Dashboard yang ditampilkan memiliki kesamaan antara login SPV, Manager, Admin (HRD).

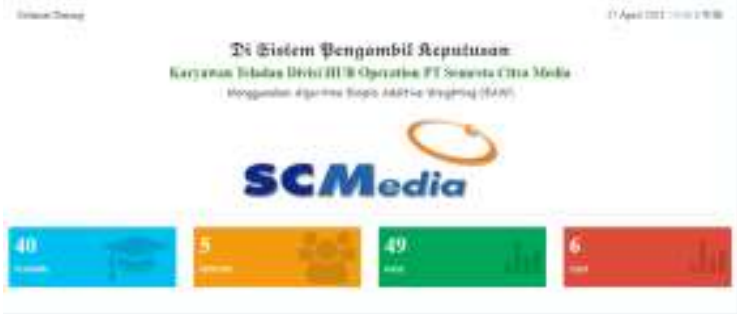

Sumber : (Hartini \& Tan, 2018)

Gambar 5. Halaman Dasboard

\section{Halaman Kriteria}

Pada halaman ini, menampilkan kriteria yang akan dinilai sesuai dari perusahaan SCMedia. Pada halaman ini hanya terdapat dipengguna Admin (HRD), yang dimana bisa melakukan create kriteria, edit kriteria, dan delete kriteria. Untuk pengguna selain HRD atau admin tidak ada akses seperti tersebut.

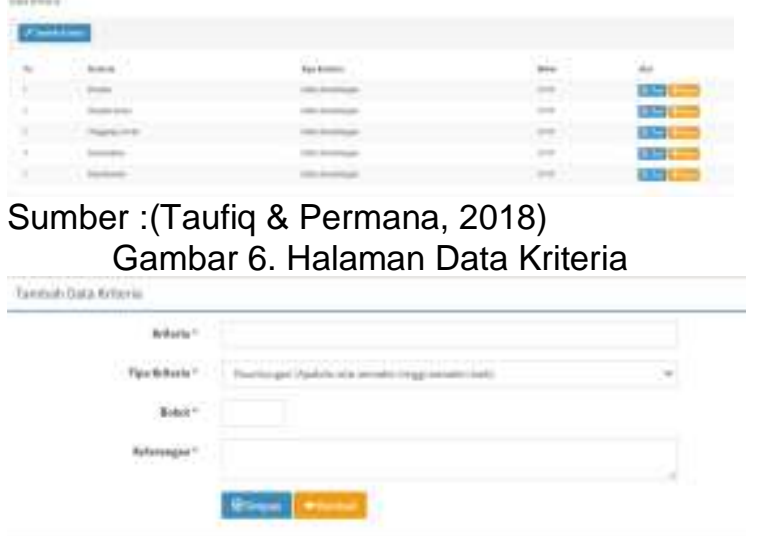

Sumber : (Taufiq \& Permana, 2018)

Gambar 7. Halaman Tambah Data Kriteria

\section{Halaman Data Alternatif}

Pada halaman ini, penulis menampilkan halaman karyawan pada divisi HUB Operation, pada halaman ini hanya terdapat di pengguna Admin (HRD) dan halaman tersebut bisa dilakukan create, update, dan delete. Pada divisi HUB Operation terdapat 40 karyawan yang akan dilakukan penilaian oleh SPV dan Manager dari bagian tersebut.
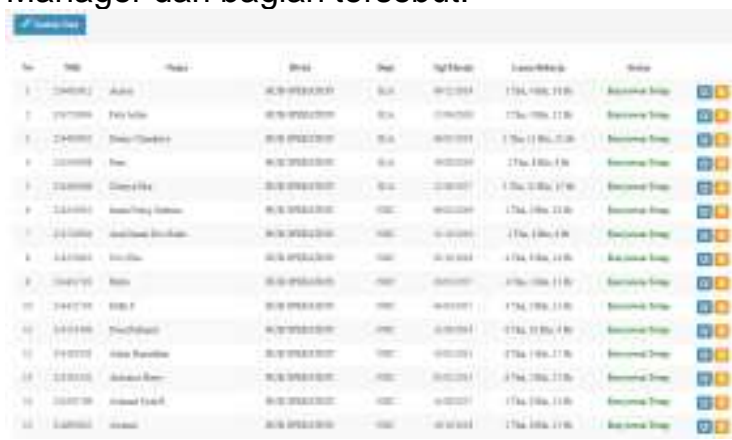

Sumber : (Taufiq \& Permana, 2018)

Gambar 8. Halaman Data Alternatif

\section{Halaman Seleksi Metode SAW}

Pada halaman ini, terdapat 2 bagian yaitu nilai alternatif dan hasil seleksi menggunakan metode saw tersebut. Halaman ini terdapat di semua data pengguna untuk melakukan penilaian dan menampilkan hasil peringkat dari 40 karyawan. Nilai alternatif berisikan, penilaian yang akan dinilai oleh SPV, yang dimana sebelum meletakkan angka di kriteria tersebut, terdapat form penilaian dari bagian bagian kriteria tersebut dengan mengklik nama karyawan terlebih dahulu seperti gambar 9, gambar 10 dan gambar 11
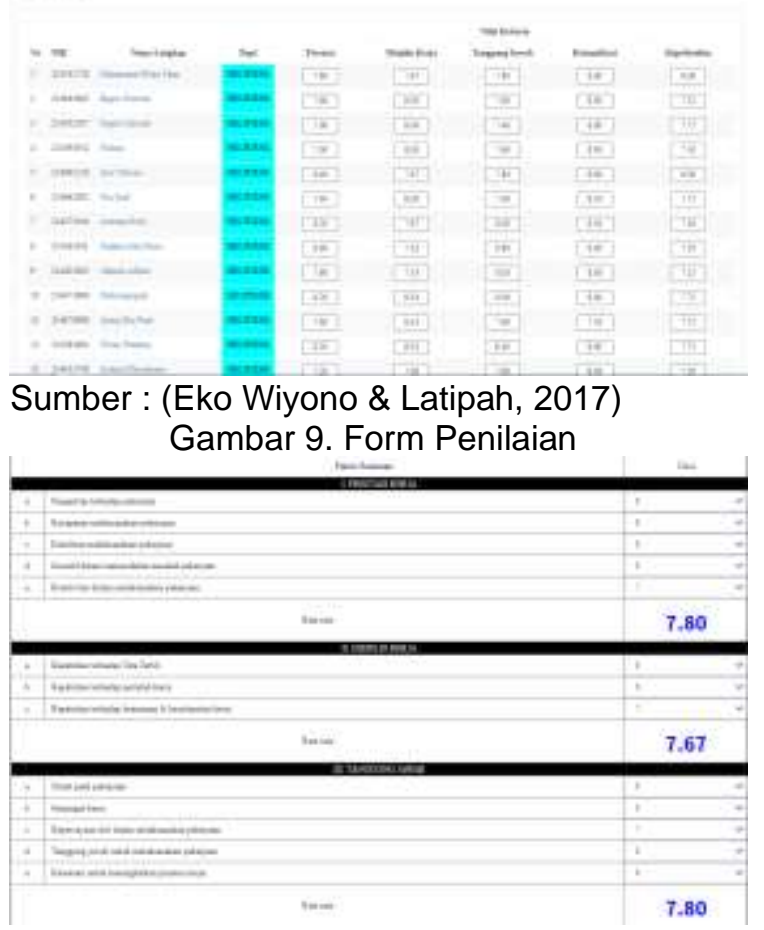

Sumber : (Eko Wiyono \& Latipah, 2017) 
Gambar 10. Form Penilaian
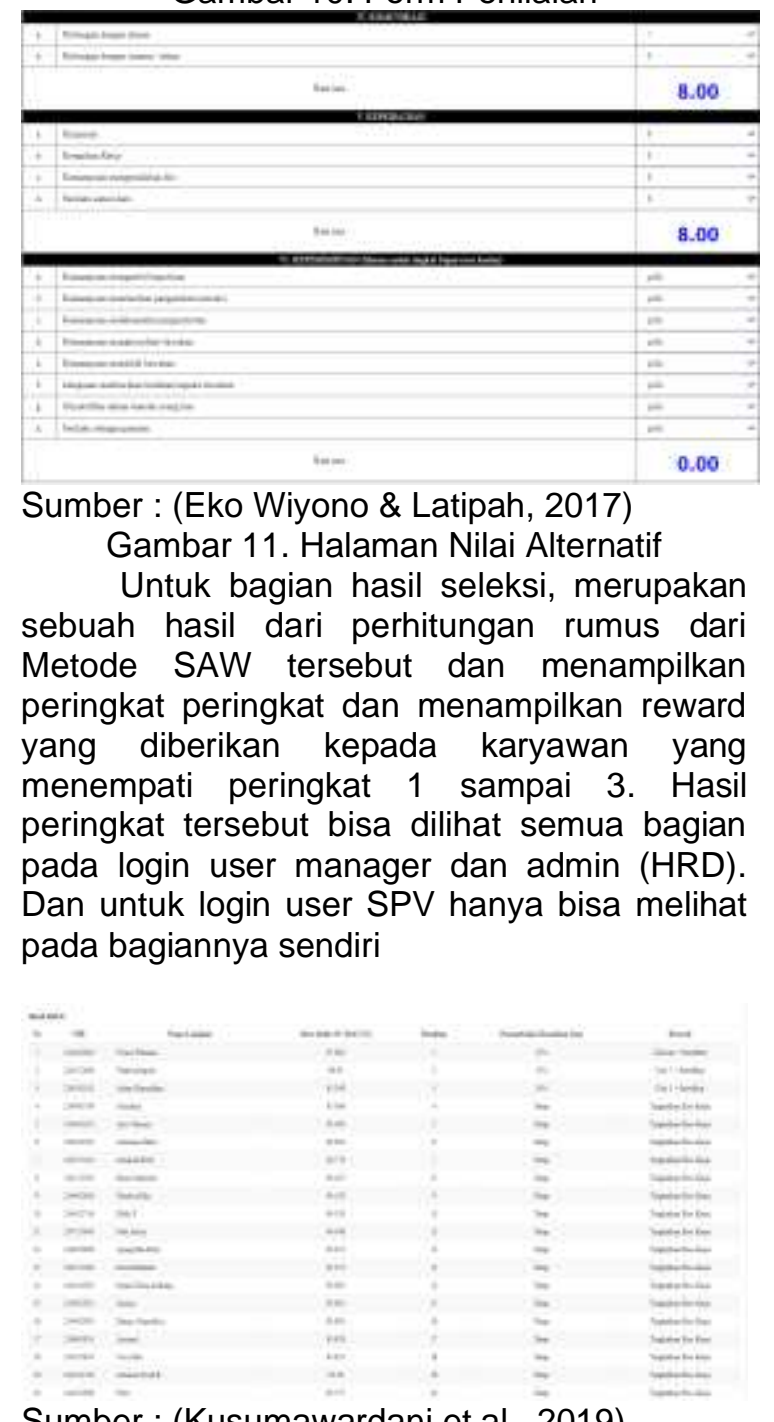

Sumber : (Kusumawardani et al., 2019)

Gambar 12. Hasil Peringkat Menggunakan Metode SAW

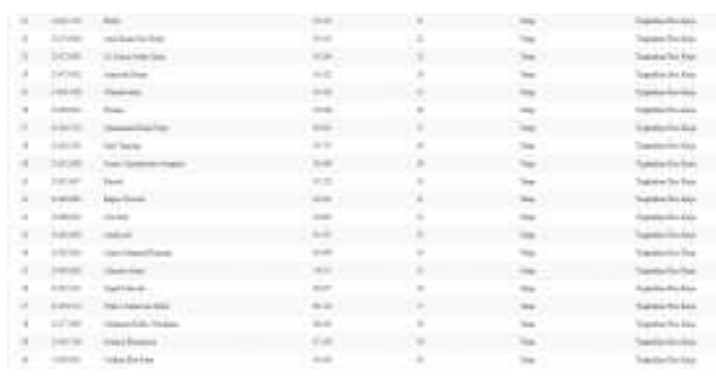

Sumber : (Kusumawardani et al., 2019)

Gambar 13. Hasil Peringkat Menggunakan Metode SAW

\section{Halaman Laporan}

Pada halaman ini, merupakan sebuah halaman seperti penyimpanan laporan tiap penilaian tersebut dengan cara meng-upload laporan yang telah didownload. Gunanya agar laporan yang disimpan di komputer hilang bisa didownload Kembali di halaman laporan tersebut.

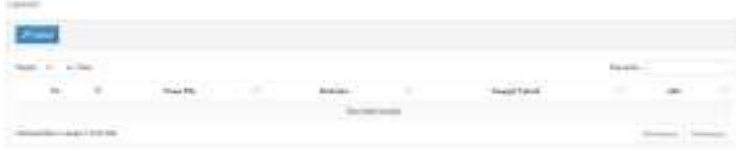

Sumber : (Alamsyah, 2020)

Gambar 14. Halaman Laporan

\section{Kesimpulan}

Bedasarkan hasil penelitian dan pengujian yang dilakukan, yang dimana pada batasan masalah penelitian ini berupa : 1. Pada penilitan ini peniliti menggunakan algoritma SAW, karena metode SAW ini mampu menyeleksi alternatif terbaik dari sejumlah pilihan, dalam hal ini alternatif pilihan yang dimaksud yaitu yang berhak menerima reward berdasarkan kriteria-kriteria yang ditentukan. Penelitian dilakukan dengan mencari nilai bobot untuk setiap atribut, kemudian dilakukan proses perankingan yang akan menentukan alternatif yang optimal, yaitu karyawan teladan. 2. Metode Simple Additive Weighting (SAW) memiliki nilai bobot dari masing-masing data kriteria. 3. Implementasi awal aplikasi ini khusus untuk kebutuhan manager HUB Operation untuk memilih karyawan teladan yang akan diajukan kepada divisi HRD. Penulis dapat menyimpulkan bahwa Sistem Pengambilan Keputusan dengan menggunakan metode Simple Additive Weighting (SAW) dapat membantu perusahaan PT SCMedia untuk mencari karyawan teladan, sehingga perusahaan tidak mencari karyawan teladan dengan manual kembali (Gunawan \& Firmansyah, 2020). Dan dari perhitungan metode SAW Pada penelitian ini meghasilkan sebuah peringkat yang dimana peringkat tersebut ber-urut dari terbesar hingga terkecil dengan mempunyai acuan kriteria prestasi kerja, disiplin kerja, tanggung jawab, komunikasi dan kepribadian sehingga terpilih menjadi karyawan teladan, dimana akan mendapakatkan sebuah penambahan kenaikan gaji dan mendapatkan sebuah penghargaan berupa liburan dan sertifikat yaitu alternatif : A18 (Wisnu Pratama) dengan skor 97,862, A10 (Wahyuningsih) degan skor 96,910, A34 (Adam Ramadhan) dengan skor 95,399. Dari hasil perhitungan tersebut dan sistem yang telah dibuat sudah memenuhi kebutuhan perusahaan untuk membantu agar lebih cepat untuk penilaian karyawan tiap dan dalam penilaian karyawan tidak dilihat dari berapa lamanya bekerja dan penilaian lebih objektif karena sudah tidak mendengarkan atau megambil opini dari berbagai sumber. 


\section{Referensi}

Adianto, T. R., Arifin, Z., Khairina, D. M., Mahakam, G., \& Palm, G. (2017). Sistem Pendukung Keputusan Pemilihan Rumah Tinggal Di Perumahan Menggunakan Metode Simple Additive Weighting (Saw) (Studi Kasus : Kota Samarinda). Prosiding Seminar IImu Komputer Dan Teknologi Informasi, 2(1), 197-201.

Alamsyah, N. (2020). SISTEM INFORMASI REKRUTMEN KARYAWAN BERBASIS WEB MENGGUNAKAN ALGORITMA SAW ( SIMPLE ADDITIVE WEIGHTING ) informasi umum seputar perusahaan Pengelolaan Sumber Daya Manusia seperti visi misi , sejarah dan kegiatan ( SDM ) merupakan hal yang penting dalam pe. Nuansa Informatika, 14(2614-5405), 31-38.

Eko Wiyono, S., \& Latipah. (2017). Penerapan Metode Simple Additive Weighting (SAW) Pada Sakinah Supermarket Untuk Pemilihan Karyawan Terbaik. Jurnal Link, 26(1), 24-28.

Gunawan, W., \& Firmansyah, M. R. (2020). Monitoring dan Evaluasi Kinerja Karyawan menggunakan Algoritma Simple Additive Weighting dan Hungarian. ILKOM Jurnal IImiah, 12(2), 87-95. https://doi.org/10.33096/ilkom.v12i2.519. 87-95

Hartini, H., \& Tan, F. (2018). Sistem Pendukung Keputusan Kenaikan Jabatan Fungsional dan Pangkat Dosen. Jurnal Sisfokom (Sistem Informasi Dan Komputer), 7(1), 38.

https://doi.org/10.32736/sisfokom.v7i1.28 7

Hutahaean, J., \& Badaruddin, M. (2020). Sistem Pendukung Keputusan Pemilihan Sekolah SMK Swasta Penerima Dana Bantuan Menerapkan Metode Simple Additive Weighting (SAW). Jurnal Media Informatika Budidarma, 4(2), 466. https://doi.org/10.30865/mib.v4i2.2109

Kusumawardani, R., Solichin, A., Informatika, P. T., Informasi, F. T., \& Luhur, U. B. (2019). Implementasi Metode Simple Additive Weighting ( Saw ) Pada. 1(3), 16.

Manajemen, J., Informasi, S., Fitri, N. Y., Studi, P., \& Sistem, M. (2017). Analisis Dan
Perancangan Sistem Pendukung Keputusan Penilaian Kinerja Guru Dengan Menggunakan Metode Simple Additive Weighting (Saw) Pada Smk Yadika Jambi. Manajemen Sistem Informasi, 2(1), 318-326.

Saefulloh, A. N., Katili, P. B., Industri, T., Sultan, U., \& Tirtayasa, A. (2017). Perancangan Sistem Penilaian Kinerja Karywan PKWT di PT Agung Mandalika dengan Metode Analytical Hierarchi Process \& Fuzzy Simple Additive Weighted. 5(2).

Sistem, R. (2017). Jurnal Resti. 1(1), 19-25.

Somya, R., \& Wahyudi, A. (2020). Sistem Pendukung Keputusan Perekrutan Karyawan Menggunakan Metode TOPSIS di PT Visionet Data Internasional. Jurnal Informatika, $\quad 7(2), \quad$ 107-115. https://doi.org/10.31294/ji.v7i2.8018

Susanto, A. B., \& Eriana, E. S. (2020). Penerapan Metode Saw Dalam Pemilihan Siswa Berprestasi Pada Smk Bistek Gunung Sindur. Jurnal Teknologi Informasi, 15(1), 36-40.

Susliansyah, S., Aria, R. R., \& Susilowati, S. (2019). Sistem Pemilihan Laptop Terbaik Dengan Menggunakan Metode Weighted Product (Wp). Jurnal Techno Nusa Mandiri, 16(1), 15-20. https://doi.org/10.33480/techno.v16i1.105

Taufiq, R., \& Permana, A. A. (2018). Sistem Pendukung Keputusan Penerimaan Karyawan Menggunakan Simple Additive Weighting Studi Kasus PT. Trafoindo Prima Perkasa. JURNAL Al-AZHAR INDONESIA SERI SAINS DAN TEKNOLOGI, 4(4), 186. https://doi.org/10.36722/sst.v4i4.309

Wahyudi, I., Bahri, S., \& Handayani, P. (2019). Aplikasi Pembelajaran Pengenalan Budaya Indonesia. V(1), 135-138. https://doi.org/10.31294/jtk.v4i2

Yogi Hermawan,. D., \& Yessy Yanitasari. (2019). Penentuan Peluang Usaha Pertanian Holtikultura Menggunakan Simple Additive Weighting dan Promethee. Jurnal RESTI (Rekayasa Sistem Dan Teknologi Informasi), 3(3), 422-428.

https://doi.org/10.29207/resti.v3i3.1255 